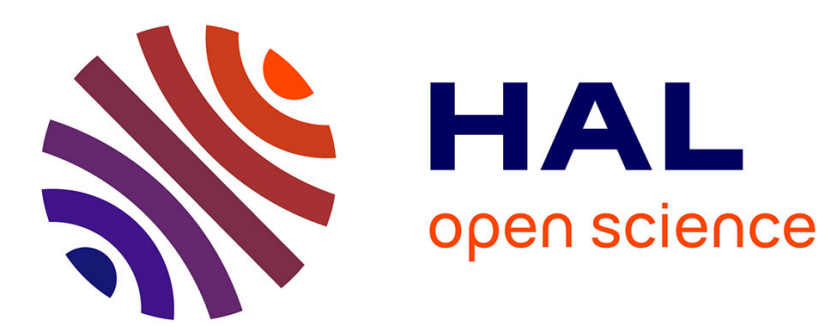

\title{
Electrogenerated Sm(II)-Catalyzed CO 2 Activation for Carboxylation of Benzyl Halides
}

\author{
Sakna Bazzi, Emmanuelle Schulz, Mohamed Mellah
}

\section{To cite this version:}

Sakna Bazzi, Emmanuelle Schulz, Mohamed Mellah. Electrogenerated Sm(II)-Catalyzed CO 2 Activation for Carboxylation of Benzyl Halides. Organic Letters, 2019, 21 (24), pp.10033-10037. 10.1021/acs.orglett.9b03927 . hal-03052936

\section{HAL Id: hal-03052936 https://hal.science/hal-03052936}

Submitted on 10 Dec 2020

HAL is a multi-disciplinary open access archive for the deposit and dissemination of scientific research documents, whether they are published or not. The documents may come from teaching and research institutions in France or abroad, or from public or private research centers.
L'archive ouverte pluridisciplinaire HAL, est destinée au dépôt et à la diffusion de documents scientifiques de niveau recherche, publiés ou non, émanant des établissements d'enseignement et de recherche français ou étrangers, des laboratoires publics ou privés. 


\title{
Electrogenerated Sm(II)-Catalyzed $\mathrm{CO}_{2}$ Activation for Carboxylation of Benzyl Halides.
}

\author{
Sakna Bazzi, Emmanuelle Schulz and Mohamed Mellah* \\ Institut de Chimie Moléculaire et des Matériaux d'Orsay (UMR CNRS 8182), Equipe Catalyse Moléculaire, Université Paris \\ Sud, Université Paris-Saclay, 15, rue Georges Clémenceau, 91405 Orsay, Cedex, France
}

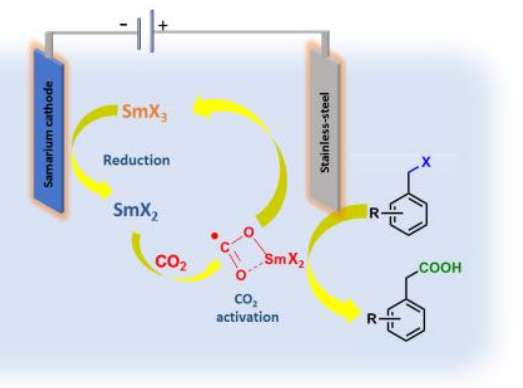

\section{Supporting Information Placeholder}

\begin{abstract}
Sm(II)-catalyzed carboxylation of benzyl halides is reported through the electrochemical reduction of $\mathrm{CO}_{2}$. The transformation proceeds under mild reaction conditions to afford the corresponding phenylacetic acids in good to excellent yields. This user-friendly and operationally simple protocol represents an alternative to traditional strategies, which usually proceeds through $\mathrm{C}\left(\mathrm{sp}^{3}\right)$-halide activation pathway.
\end{abstract}

Currently, carbon dioxide $\left(\mathrm{CO}_{2}\right)$ represents one of the major contributors to the greenhouse effect in the atmosphere. Thus, in the past decade, scientists, notably organic chemists, have dedicated substantial research efforts to find ways to fix $\mathrm{CO}_{2}$ and to convert it into valuable chemicals. ${ }^{1-3}$ The difficulty is that, due to the thermodynamic stability of its $\mathrm{CO}$ bond, the insertion of $\mathrm{CO}_{2}$ into an organic moiety remains challenging, especially if we aim at high reactivities and functional group tolerance. Nucleophiles such as Grignard and organolithium reagents are typically required for direct activation of $\mathrm{CO}_{2}{ }^{2,3}$ Recent advances in catalysis and electrochemistry have independently provided efficient solutions for the chemical transformation of $\mathrm{CO}_{2}$ (Scheme 1).

Scheme 1. Carboxylation strategies for the preparation of phenylacetic acids using $\mathrm{CO}_{2}$ as a $\mathrm{C}-1$ building block

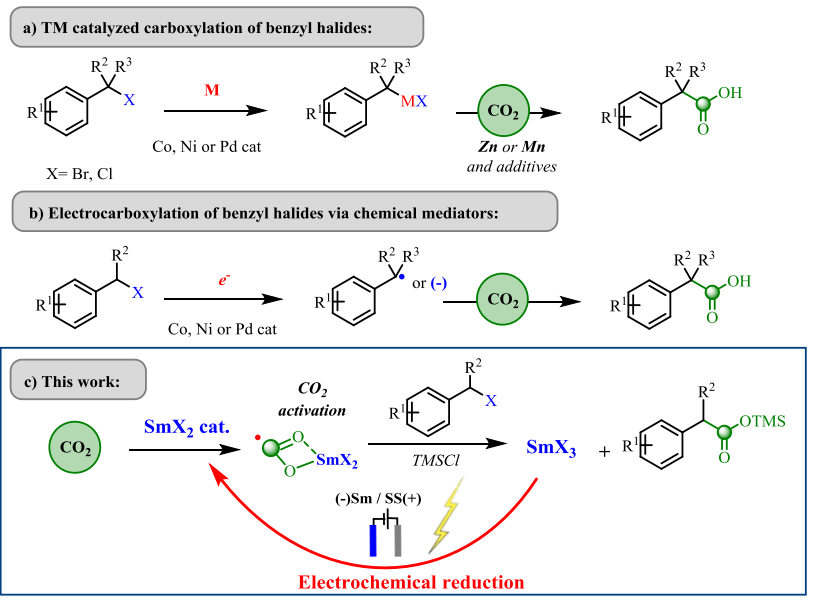

Carboxylic acids, which are high-added-value industrial compounds are in general the most targeted products for this type of transformation. More specifically, phenylacetic acids have received increasing attention as their scaffolds can be found in drugs that are used on a daily basis (e.g., ibuprofen, naproxen). ${ }^{4}$ In recent years, elegant metal-catalyzed reactions were developed to produce phenylacetic acids from styrene derivatives ${ }^{5}$ or organozinc reagents. ${ }^{6}$ In 2013, Martin and co-workers described the first catalytic carboxylation of primary benzyl chlorides, featuring a nickel-based catalytic system, to generate phenylacetic acids. ${ }^{7}$ Although remarkable, this reaction still required the use of over-stoichiometric amounts of $\mathrm{Zn}$ and $\mathrm{MgCl}_{2}{ }^{8}$.

Electrochemistry represents a viable alternative by eliminating the use of toxic and hazardous reducing agents., ${ }^{9,10}$ Major advances have been made with the use of sacrificial anodes (e.g. $\mathrm{Mg}, \mathrm{Al}$ ), which enabled the in situ formation of an organometallic species. ${ }^{11}$ In general, the electrocarboxylation of benzyl halides involves an initial reduction, forming either the benzyl radical or the anion, which can then react with $\mathrm{CO}_{2}$ to yield phenylacetic 
acid. The $\mathrm{CO}_{2}$ activation offers probably an alternative to reach more efficient carboxylation by avoiding the side products resulting from dehalogenation or dimerization, which are common drawbacks in all these transformations. ${ }^{7}$ To the best of our knowledge, the direct carboxylation of alkyl halides starting with $\mathrm{CO}_{2}$ reduction has not yet been described in the literature.

Recently, we reported a procedure for the carboxylation of aryl halides with the use of a "soluble" Sm anode, affording functionalized benzoic acids from aryl chlorides. We demonstrated that the electrolysis enabled the generation in situ of a powerful $\mathrm{Sm}(\mathrm{II})$ species, which directly reduced $\mathrm{CO}_{2}{ }^{12} \mathrm{We}$ depict herein our findings on the catalytic carboxylation of benzyl halides via $\mathrm{CO}_{2}$ activation promoted by electrochemically generated $\mathrm{Sm}(\mathrm{II})$ species to access highly sought-after phenylacetic acids, including Naproxen.

As a first step, we explored the carboxylation of benzyl chloride (1a) as a benchmark reaction, using a Sm anode to produce $\mathrm{Sm}$ (II) reagent under 1 atm $\mathrm{CO}_{2}$ (Figure 1). We performed the electrolysis in an undivided cell under standard stoichiometric conditions. ${ }^{12}$ The reaction was implemented by introducing $\mathbf{1 a}$ in a solution of $n \mathrm{Bu}_{4} \mathrm{NBF}_{4}$ in DMF with a continuous bubbling of $\mathrm{CO}_{2}$.
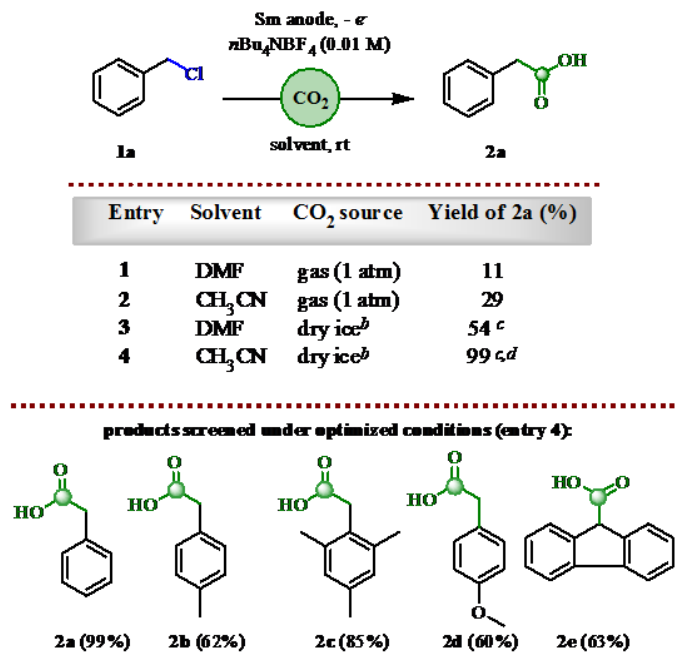

Figure 1. Electrocarboxylation of 1a using Sm "soluble" anode $^{a}$

a Standard stochiometric conditions: Undivided cell, fitted with two electrodes a samarium anode (diameter $\operatorname{rod}=1 \mathrm{~cm}$ ) and a stainless-steel cathode grid $\left(20 \mathrm{~cm}^{2}\right)$, 1a $(5 \mathrm{mmol})$, solvent $(50 \mathrm{~mL}), 4$ hours at $0.1 \mathrm{~A}$. Isolated yields; ${ }^{b}$ the temperature was monitored during the addition of dry ice, and it remained between $20-23^{\circ} \mathrm{C},{ }^{c} \mathbf{1 a}(1 \mathrm{mmol})$ after $2 \mathrm{~h},{ }^{d} n \mathrm{Bu}_{4} \mathrm{NBF}_{4}$ (0.04 M).

The reaction occurred with low conversion and led to the formation of acid 2a in a low yield (Figure 1, entry 1), which could be improved to $29 \%$ by replacing DMF with $\mathrm{CH}_{3} \mathrm{CN}$ (Figure 1, entry 2). This result is likely due to the higher solubility of $\mathrm{CO}_{2}$ in $\mathrm{CH}_{3} \mathrm{CN}$ (0.59 $\mathrm{M}$ versus $0.38 \mathrm{M}$ in DMF). ${ }^{13}$ In order to increase the availability of $\mathrm{CO}_{2}$ in solution, dry ice was employed and, to our delight, 2a was obtained in quantitative yield (Figure 1 , entry 4). Then, we evaluated the scope of the carboxylation with a series of benzyl chlorides. The corresponding phenylacetic acids were obtained in yields ranging from 60 to $99 \%$ (Figure 1). It is noteworthy that this carboxylation was not limited to primary benzyl chlorides but could be also extended to secondary benzyl chlorides (see 2e in Figure 1).

We then turned our attention to the establishement of a catalytic version (Table 1). Building on our precedent reports regarding the implementation of catalytic procedures, ${ }^{14}$ we conducted a preelectrolysis using a solution of $n \mathrm{Bu}_{4} \mathrm{NBF}_{4}[0.02 \mathrm{M}]$ in $\mathrm{CH}_{3} \mathrm{CN}$ at a constant current intensity of $0.1 \mathrm{~A}$. This first step was carried out to generate $20 \mathrm{~mol} \%$ of $\mathrm{Sm}$ (II) with respect to the substrate $(1.0$ mmol). The benzyl chloride 1a and an oxophilic reagent (3.0 equiv.) were then added to the solution. From there, the polarity of the electrode was inverted to act as a cathode ${ }^{15}$ throughout the electrolysis, achieved at a constant current intensity of $0.1 \mathrm{~A}$. It is important to stress that the use of an oxophilic reagent is critical in catalytic processes involving $\mathrm{SmI}_{2} \cdot{ }^{16,17}$ Indeed, this additive promotes the cleavage of the $\mathrm{Sm}^{\text {III }}-\mathrm{O}$ bonds. In this way, the released trivalent $\mathrm{Sm}$ (III) species can be reduced onto the cathode to regenerate the $\mathrm{Sm}$ (II) active species. The use of TMSOTf resulted in the formation of the targeted acid $\mathbf{2 a}$ in $45 \%$ yield. Interestingly, switching from TMSOTf to TMSCl increased the yield to $60 \%$ (Table 1, entry 1 and 2). Various Brønsted acids were also screened as a proton source (Table 1, entry 3-5) in the hope that the resulting Sm salts could be reduced without having to rely on a Si-based additive. However, the reactions were completely shut down, and 1a remained intact. The effect of Sm ligand was also evaluated by replacing $n \mathrm{Bu}_{4} \mathrm{NBF}_{4}$ by $n \mathrm{Bu}_{4} \mathrm{NOTf}$, but it did not have a significant impact (Table 1, entry 6).

Table 1. Electrogenerated Sm(II)-catalyzed carboxylation of benzyl chloride 1a. ${ }^{a, b}$

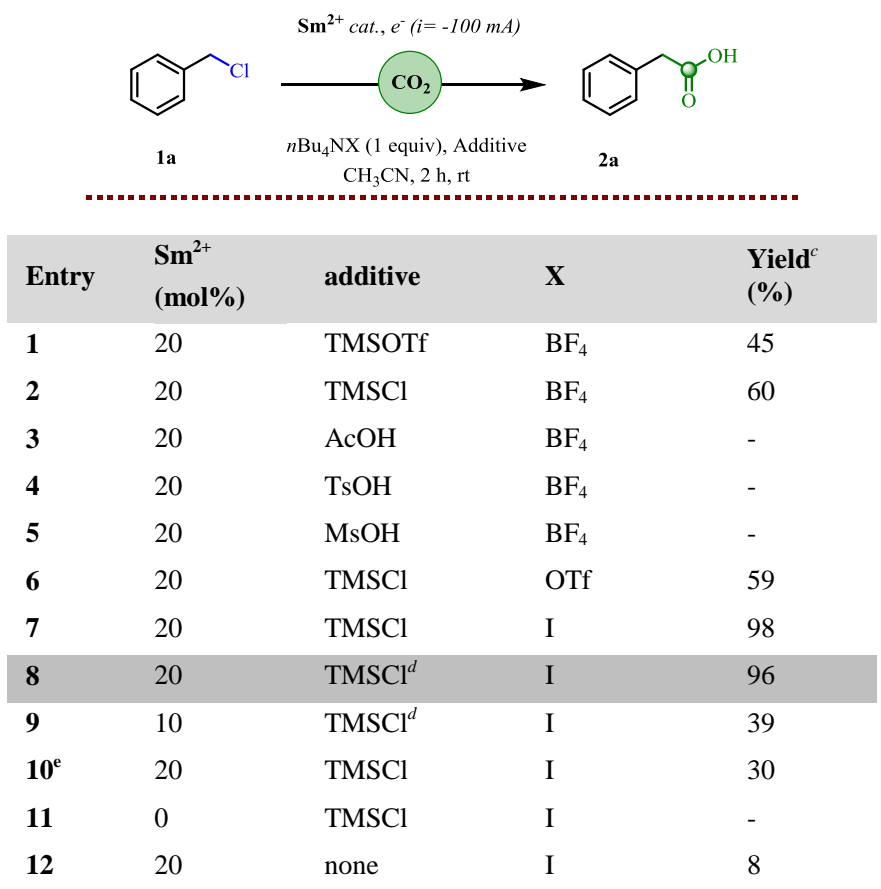

a Reaction conditions: anode of samarium (rod) and cathode of stainless-steel grid $(20 \mathrm{~cm} 2)$, with a solution of $n \mathrm{Bu}_{4} \mathrm{NX}$ (1 equiv) in $\mathrm{CH}_{3} \mathrm{CN}(50 \mathrm{~mL})$. The electrolysis was performed for 386 seconds at $\mathrm{i}=$ $100 \mathrm{~mA}$, before switching the polarity of the electrodes and adding dry ice, $1 \mathbf{a}(1 \mathrm{mmol})$ and the additive $(3 \mathrm{mmol})$. Dry ice was added in small pieces each $15 \mathrm{~min} ;{ }^{b}$ the temperature was monitored during the addition of dry ice, and it remained between $20-23^{\circ} \mathrm{C} ;{ }^{c}$ Isolated yields; ${ }^{d}$ TMSCl 1.5 mmol. ${ }^{e}$ Glassy carbon cathode instead of Sm cathode. 
In contrast, the use of $n \mathrm{Bu}_{4} \mathrm{NI}$ improved drastically the reactivity, providing 2a in $98 \%$ yield and the amount of TMSCl could be lowered to 1.5 equivalent without being detrimental to the outcome of the electrocarboxylation (Table 1, entry 7, 8). Eventually, we found out that using a catalytic loading of 20 mol\% was essential for a smooth functioning of the reaction. Control experiments were carried out to ascertain the role of each parameter. Thus, the use of a glassy carbon cathode instead of a samarium one furnished 2a in only $30 \%$ yield, which confirmed the need for a $\mathrm{Sm}$ cathode in order to efficiently regenerate the Sm(II) catalytic species. ${ }^{14 a}$ The direct reduction onto the $\mathrm{Sm}$ cathode without catalyst left $\mathbf{1 a}$ intact (Table 1, entry 11). As anticipated, the catalytic turnover cannot be achieved without TMSCl as only $8 \%$ of $\mathbf{2 a}$ was isolated (Table 1 , entry 12 ). With these optimized conditions in hand, we explored the scope of the reaction by using a series of commercially available benzyl chlorides and bromides (Scheme 2). We were pleased to find that the transformation tolerated a wide range of substituted benzyl halides bearing both electron-donating (1b-1d and 1f-g) and withdrawing groups (1h-1m). Besides, our electrocatalytic reaction demonstrated excellent chemoselectivity. Accordingly, additional functionalities (halides (2h, $\mathbf{2} \mathbf{i}$, and $\mathbf{2} \mathbf{k}$ ), esters (2m), and alkenes (2n)) remained intact without any dehalogenation or dicarboxylation side reactions. The reaction was not precluded by the presence of ortho substituents $(\mathbf{2 c}, \mathbf{2} \mathbf{i}$, and $\mathbf{2 k})$. Of note, benzyl bromides could be also subjected to the carboxylation conditions to access similar compounds in higher yields ( see $\mathbf{2 b}, \mathbf{2 d}, \mathbf{2} \mathbf{f}$, and 2n). Another interesting trademark is the excellent reactivity of secondary benzyl chlorides, which gave the relevant products with no yield drop (2e and $\mathbf{2 0 - 2 t )}$.

\section{Scheme 2. Sm(II)-catalyzed electrocarboxylation of benzyl chlorides ${ }^{a}$}

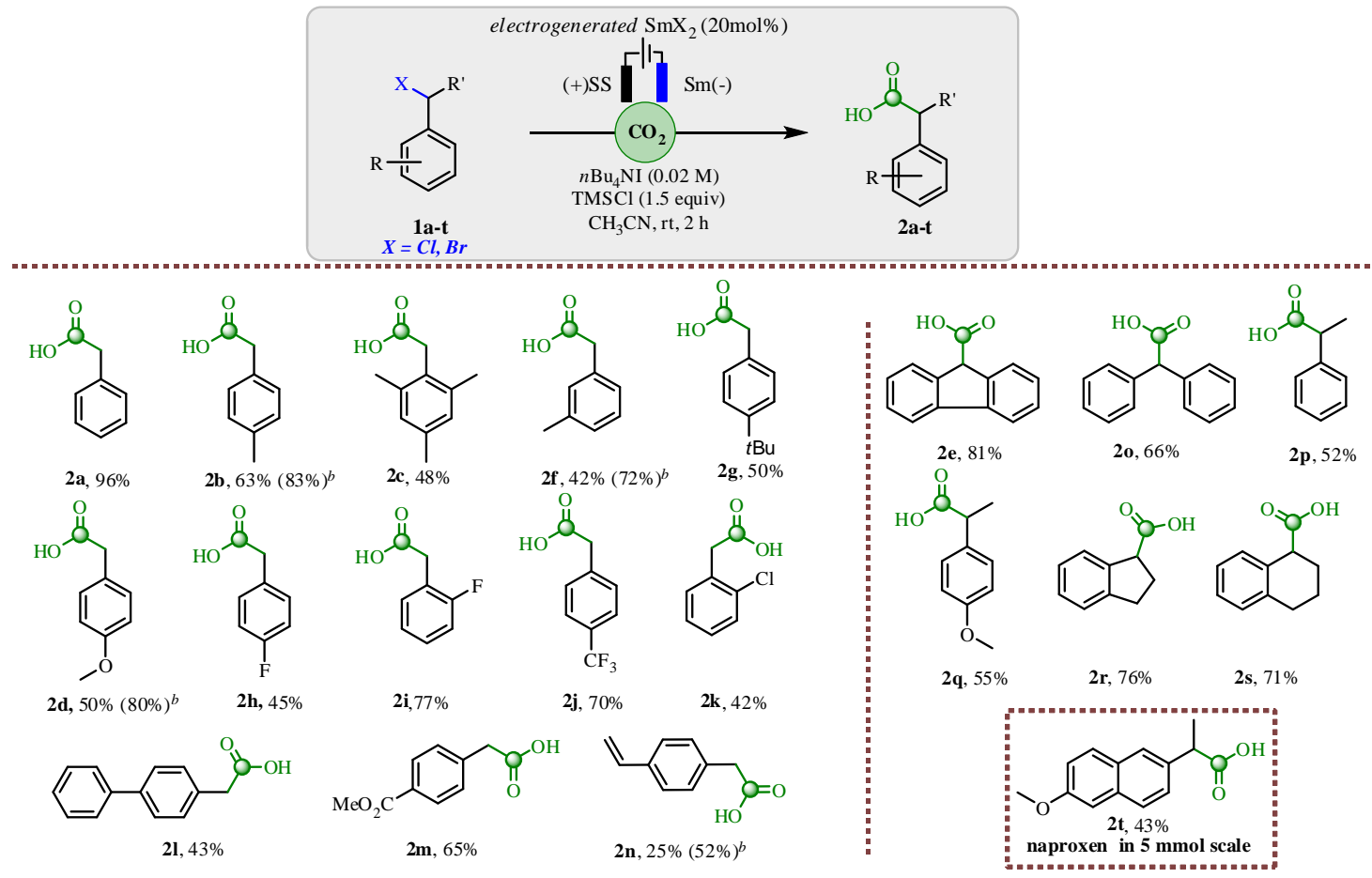

${ }^{a}$ Standard catalytic conditions: Undivided cell, fitted with two electrodes: cathode of samarium rod (diameter $\left.1 \mathrm{~cm}\right)$ and anode of stainless-steel grid (20 $\left.\mathrm{cm}^{2}\right), \mathrm{i}=100 \mathrm{~mA},(\mathbf{1 a})(1 \mathrm{mmol}), n \mathrm{Bu}_{4} \mathrm{NI}(1 \mathrm{mmol}), \mathrm{TMSCl}(1.5 \mathrm{mmol})$, solvent $(50 \mathrm{~mL}), 2 \mathrm{~h}$. Dry ice was added in small pieces each $15 \mathrm{~min} .{ }^{b}$ Isolated yields obtained from benzyl bromides.

It is even more appealing when one considers the low propensity of secondary alkyl chlorides to undergo oxidative addition in organometallic-based strategies, making their carboxylation still challenging. ${ }^{7,18}$ Finally, as a proof of the robustness of our electrocatalytic process, we succeeded to prepare ( \pm )Naproxen $\mathbf{2 t}$ in $43 \%$ yield on a $5 \mathrm{mmol}$ scale. Then, we conducted complementary experiments to gain some insight into the mechanism (Figure 2 and SI for details). Therefore, the electrolysis was performed in the absence of benzyl chloride, which produced a white-grey precipitate. ${ }^{13} \mathrm{C}-\mathrm{NMR}$ of the crude reaction mixture revealed the formation of oxalic acid, demonstrating that the samarium can reduce efficiently $\mathrm{CO}_{2}$.
Furthermore, running the electrolysis without $\mathrm{CO}_{2}$ let $\mathbf{1 a}$ intact. Both experiments clearly confirmed that the carboxylation was initiated by the reaction between the $\mathrm{CO}_{2}$ radical anion and the benzyl chloride. The influence of the samarium ligand was also evaluated by carrying out the electrocatalytic carboxylation with chloride as the only possible source of ligand for samarium, using benzyl chloride, TMSCl and $20 \mathrm{~mol} \%$ of $\mathrm{SmCl}_{3}$ as a catalyst (see SI). The reaction delivered the phenylacetic acid in $75 \%$ yield, indicating that the ligand exchange was not the key step of the electrocarboxylation. 


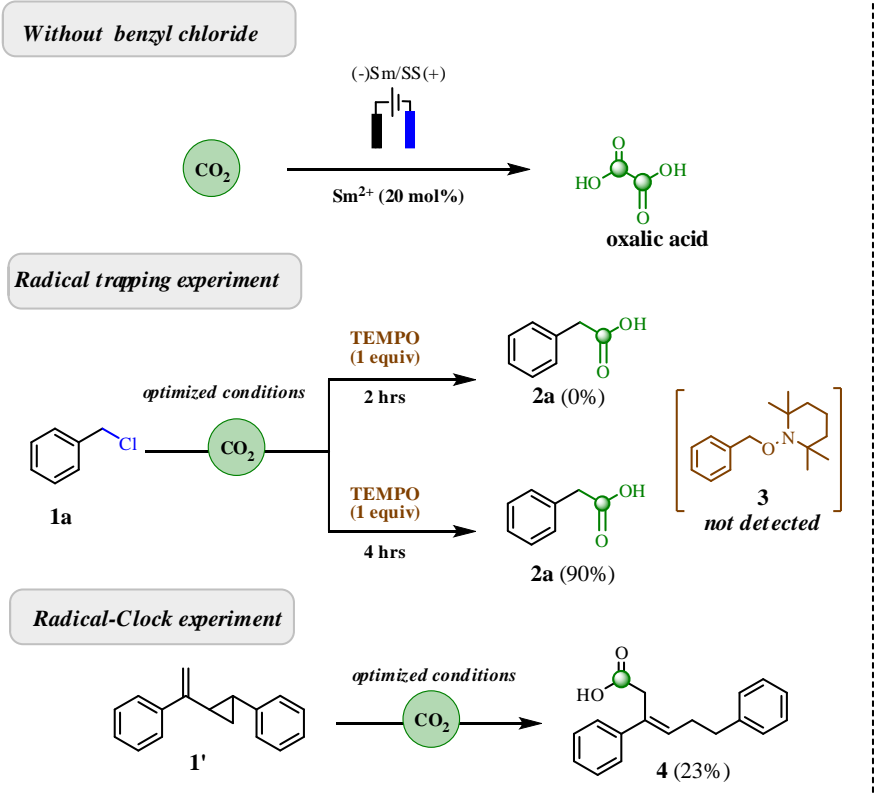

Electrochemical analysis

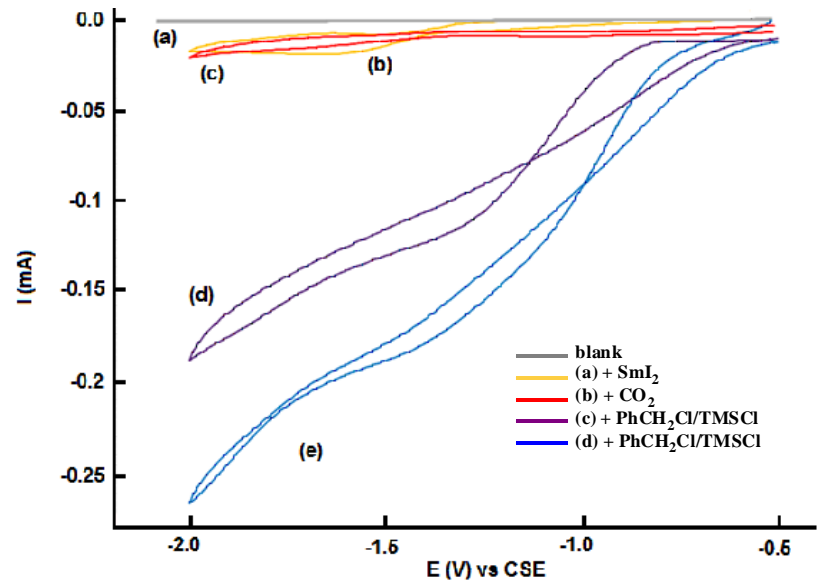

Figure 2. Preliminary mechanistic experiments

Cyclic voltammetry conditions: Glassy carbon working electrode (surface $20 \mathrm{~mm}^{2}$ ), Pt wire as counter electrode and SCE reference, scanning potential between -0.5 and $-2 \mathrm{~V}$ in $\mathrm{CH}_{3} \mathrm{CN}$ with $n \mathrm{Bu}_{4} \mathrm{NPF}_{6}[0.1 \mathrm{M}]$. Scan rate: $100 \mathrm{mV} / \mathrm{s}$. (a) : $n \mathrm{Bu}_{4} \mathrm{NPF}_{6}[0.1 \mathrm{M}]$ in $\mathrm{CH}_{3} \mathrm{CN}$; (b) : after introducing $0.2 \mathrm{M}$ of electrogenerated $\mathrm{SmI}_{2} ;$ (c) : After addition of dry ice to the solution (b); (d): Addition of $0.5 \mathrm{~mL}$ of $\mathrm{CH}_{3} \mathrm{CN}$ solution containing $\mathrm{BnCl}[1 \mathrm{M}$ ] and TMSCl [1.5 $\mathrm{M}$; (e): Addition of $0.5 \mathrm{~mL}$ of $\mathrm{CH}_{3} \mathrm{CN}$ solution containing $\mathrm{BnCl}$ [1 M] and TMSCl [1.5 M] to solution (d).

In addition, radical trapping experiments were performed by adding TEMPO (1 equiv.) to the reaction mixture (Figure 2). Even though the TEMPO was completely consumed, the formation of product $\mathbf{3}$ was not observed, which suggests that the generation of the benzyl radical did not occur. It is also noteworthy that 2a was not obtained either. On the other hand, prolonging the electrolysis time to 4 hours afforded $\mathbf{2 a}$ in a $90 \%$ yield. Thus, we assumed that TEMPO had quenched the $\mathrm{CO}_{2}$ radical anion in the first place but, after the complete consumption of the radical scavenger, the reactivity could be restored to yield 2a. Moreover, a radical clock experiment was performed with the aim of isolating a compound resulting from the insertion of $\mathrm{CO}_{2}$. Indeed, the reaction led to product 4 in $23 \%$ yield, providing further evidence of the $\mathrm{CO}_{2}$ radical anion formation. Finally, cyclic voltammetry measurements were conducted to assess the redox behavior of the catalyst. In the absence of $\mathrm{CO}_{2}$, the quasireversible $\mathrm{Sm}(\mathrm{III}) / \mathrm{Sm}$ (II) system was observed at - $1.4 \mathrm{~V} / \mathrm{SCE}$. Once $\mathrm{CO}_{2}$ was introduced, a weak reduction wave was noticed with a potential shift around $-1.8 \mathrm{~V} / \mathrm{SCE}$ and the oxidation wave disappeared. This behavior confirmed the chemical interaction between $\mathrm{Sm}(\mathrm{II})$ and $\mathrm{CO}_{2}$. Then, the addition of a mixture of substrate 1a and $\mathrm{TMSCl}$ (ratio 1:1.5) triggered a significant reduction wave, which started at $-0.95 \mathrm{~V} / \mathrm{SCE}$ and increased significantly upon further addition of this mixture. Overall, this electrochemical behavior of the catalyst proves the appearance of a catalytic current.

Based on these experiments, the following mechanism is proposed for this electrochemical process (Scheme 3). Initially, $\mathrm{Sm}$ (II) could reduce the carbon dioxide into the $\mathrm{CO}_{2}$ radical anion $\mathbf{A}$, before being engaged in a radical substitution with benzyl chloride to produce the samarium carboxylate intermediate $\mathbf{B}$. Then, TMSCl would furnish the silyl ester $\mathbf{C}$, which leads to the carboxylic acid 2a upon treatment. Finally, the catalyst would be recovered by reduction onto the samarium cathode.

\section{Scheme 3. Proposed mechanism.}

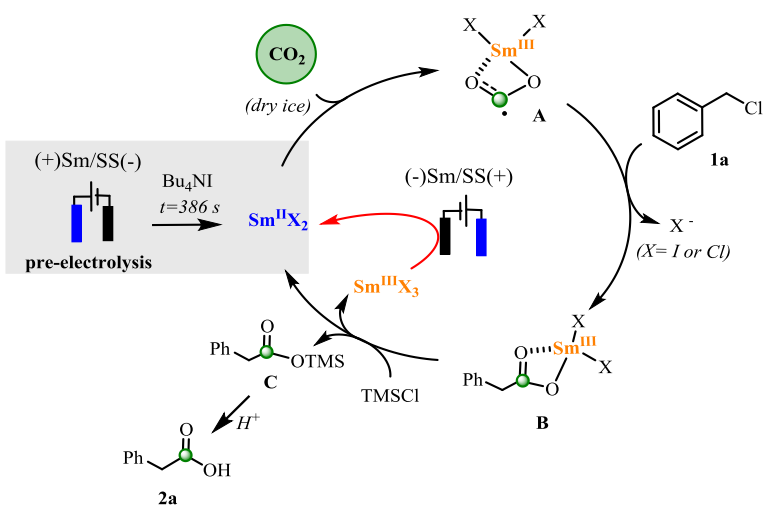

In conclusion, we have devised a novel catalytic carboxylation of primary and secondary benzyl halides relying on electrogenerated $\mathrm{SmI}_{2}$. When compared to previous reports, this electrocarboxylation process proceeds through a different pathway involving a $\mathrm{CO}_{2}$ activation instead of $\mathrm{C}\left(\mathrm{sp}^{3}\right)$-halide one. This approach represents an alternative to other existing $\mathrm{CO}_{2}$ fixation methodologies that require the preparation of welldefined and sensitive organometallic reagents. This catalytic process provides streamline access to valuable phenylacetic acids, including Naproxen. Further developments of an enantioselective carboxylation reaction and an extension to unactivated alkyl halides are currently under investigation.

\section{ASSOCIATED CONTENT}

\section{Supporting Information}

The Supporting Information is available free of charge on the ACS Publications. Experimental procedures, compounds data, and spectra.

\section{AUTHOR INFORMATION}

\section{Corresponding Author}


* mohamed.mellah@u-psud.fr

\section{Author Contributions}

\section{Notes}

The authors declare no competing financial interests.

\section{ACKNOWLEDGMENT}

We thank the CNRS, the Ministère de l'Enseignement Supérieur et de la Recherche and the Charm3at LABEX(ANR-11-Labex0039). We also thank Dr. David Leboeuf (ICMMO-UMR CNRS 8182) for fruitful discussions.

\section{REFERENCES}

(1) Liu, Q.; Wu, L.; Jackstell R.; Beller, M. Using Carbon Dioxide as a Building Block in Organic Synthesis. Nat. Commun. 2015, 6, 1-15.

(2) (a) Sakakura, T.; Choi, J.-C.; Yasuda, H. Transformation of Carbon Dioxide. Chem. Rev. 2007, 107, 2365-2387. (b) Mikkelsen, M.; Jorgensen, M.; Krebs, F. C. The Teraton Challenge. A Review of Fixation and Transformation of Carbon Dioxide. Energy Environ. Sci. 2010, 3, 4381. (c) Maeda, C.; Miyazaki, Y.; Ema, T. Recent Progress in Catalytic Conversions of Carbon Dioxide. Catal. Sci. Technol. 2014, 4, 1482-1497.

(3) For recent reviews dealing with the use of $\mathrm{CO}_{2}$, see: (a) Tsuji, Y.; Fujihara, T. Carbon Dioxide as a Carbon Source in Organic Transformation: Carbon-Carbon Bond Forming Reactions by TransitionMetal Catalysts. Chem. Commun. 2012, 48, 9956-9964. (b) Cokoja, M.; Bruckmeier, C.; Rieger, B.; Herrmann, W. A.; Kühn, F. E. Transformation of Carbon Dioxide with Homogeneous Transition-Metal Catalysts: A Molecular Solution to a Global Challenge? Angew. Chem., Int. Ed. 2011, 50, 8510-8537. (c) Martin, R.; Kleij, A. W. Myth or Reality? Fixation of Carbon Dioxide into Complex Organic Matter under Mild Conditions. ChemSusChem 2011, 4, 1259-1263. (d) Huang, K.; Sun, C.-L.; Shi, Z.-J. Transition-Metal-Catalyzed C-C Bond Formation Through the Fixation of Carbon Dioxide. Chem. Soc. Rev. 2011, 40, 2435-2452. (e) Correa, A.; Martin, R. Metal-Catalyzed Carboxylation of Organometallic Reagents with Carbon Dioxide. Angew.Chem., Int. Ed. 2009, 48, 6201-6204; (f) Tortajada, A.; Juliá-Hernández, F.; Börjesson, M.; Moragas, T.; Martin,R. Transition-Metal-Catalyzed Carboxylation Reactions with Carbon Dioxide. Angew. Chem. Int. Ed. 2018, 57, 15948-15982. (g) Yang, Y.; Lee, J.-W. Toward Ideal Carbon Dioxide Functionalization, Chem. Sci. 2019, 10, 3905-3926.

(4) Maag H. Prodrugs of Carboxylic Acids. In:Prodrugs: New York, NY: Springer, 2007, 703-729.

(5) (a) Greenhalgh, M. D.; Thomas, S. P. Iron-Catalyzed, Highly Regioselective Synthesis of $\alpha$-Aryl Carboxylic Acids from Styrene Derivatives and $\mathrm{CO}_{2}$. J. Am. Chem. Soc. 2012, 134, 11900-11903. (b) Williams, C. M.; Johnson, J. B.; Rovis, T. Nickel-Catalyzed Reductive Carboxylation of Styrenes Using $\mathrm{CO}_{2}$. J. Am. Chem. Soc. 2008, 130, 14936-14937. (c) Hoberg, H.; Peres, Y.; Kruger, C.; Tsay, Y.-H. A 1-Oxa2-nickela-5-cyclopentanone from Ethene and Carbon Dioxide: Preparation, Structure, and Reactivity. Angew. Chem. Int. Ed. 1987, 26, $771-773$.

(6) (a) Metzger, A.; Bernhardt, S.; Manolikakes, G.; Knochel, P. $\mathrm{MgCl}_{2}$-Accelerated Addition of Functionalized Organozinc Reagents to Aldehydes, Ketones, and Carbon Dioxide. Angew. Chem. Int. Ed. 2010, 49, 4665-4668. (b) Bernhardt, S.; Metzger, A.; Knochel, P. Direct
Addition of Functionalized Organozinc Reagents to Carbon Dioxide, Ketones, and Aldehydes in the Presence of $\mathrm{MgCl}_{2}$. Synthesis 2010, 38023810 .

(7) León, T.; Correa, A.; Martin R. Ni-Catalyzed Direct Carboxylation of Benzyl Halides with $\mathrm{CO}_{2}$. J. Am. Chem. Soc. 2013, 135, 1221-1224.

(8) Sayyed, F. B.; Sakaki, S. The Crucial Roles of $\mathrm{MgCl}_{2}$ as a NonInnocent Additive in the Ni-catalyzed Carboxylation of Benzyl Halide with $\mathrm{CO}_{2}$. Chem. Commun. 2014, 50, 13026-13029.

(9) Senboku H. Electrochemical Fixation of Carbon Dioxide. Bhanage, B.M.; Arai M. (Eds.), Transformation and Utilization of Carbon Dioxide, Springer-Verlag, Berlin Heidelberg 2014, 245-262

(10) (a) Matthessen, R.; Fransaer, J.; Binnemans, K.; De Vos. D.E.; Electrocarboxylation: Towards Sustainable and Efficient Synthesis of Valuable Carboxylic Acids. Beilstein J. Org. Chem. 2014, 10, 2484-2500. (b) Yan, M.; Kawamata, Y.; Baran, P. S. Synthetic Organic Electrochemical Methods Since 2000: On the Verge of a Renaissance. Chem. Rev. 2017, 117, 13230-13319.

(11) (a) Silvestri, G.; Gambino, S.; Filardo G.; Gulotta, A. Sacrificial Anodes in the Electrocarboxylation of Organic Chlorides. Angew. Chem. Int. Ed., 1984, 23, 979-980; (b) Senboku H.; Katayama, A. Electrochemical Carboxylation with Carbon Dioxide. Curr. Opin. Green Sustain. Chem., 2017, 3, 50-54; (c) Sock, O.; Troupel, M.; Périchon, J. Electrosynthesis of Carboxylic Acids from Organic Halides and Carbon Dioxide. Tetrahedron Lett., 1985, 26, 1509-1512.

(12) Bazzi, S.; Le Duc, G.; Schulz, E.; Gosmini, C.; Mellah, M. $\mathrm{CO}_{2}$ Activation by Electrogenerated Divalent Samarium for Aryl Halides Carboxylation. Org. Biomol. Chem. 2019, 17, 8546-8550.

(13) Gennaro, A.; Isse, A.; Vianello, E., Solubility and Electrochemical Determination of $\mathrm{CO}_{2}$ in Some Dipolar Aprotic Solvents. J. Electroanal. Chem. 1990, 289, 203-215.

(14) (a) Sun, L.; Sahloul K.; Mellah, M. Use of Electrochemistry to Provide Efficient $\mathrm{SmI}_{2}$ Catalytic System for Coupling Reactions. ACS Catal. 2013, 3, 2568-2573.; (b) Zhang Y.-F.; Mellah, M. Convenient Electrocatalytic Synthesis of Azobenzenes from Nitroaromatic Derivatives Using $\mathrm{SmI}_{2}$. ACS Catal. 2017, 7, 8480-8486.

(15) When the samarium electrode is used as the cathode, this later is not consumed allowing its use for a very long time. Of note, before each electrolysis, the Sm electrode is polished and simply washed with acetone.

(16) (a) Nomura, R.; Matsuno, T.; Endo, T. Samarium IodideCatalyzed Pinacol Coupling of Carbonyl Compounds. J. Am. Chem. Soc. 1996, 118, 11666-11667. (b) Aspinall, H. C.; Greeves, N.; Vallas, C. Samarium Diiodide-Catalyzed Diastereoselective Pinacol Couplings. Org. Lett. 2005, 7, 1919-1922. (c) Orsini, F.; Lucci, E. M. Reformatsky Reactions with SmI2 in Catalytic Amount. Tetrahedron. Lett. 2005, 46 , 1909-1911. (d) Corey, E. J.; Zang, G. Z. Catalytic Reactions of Samarium (II) Iodide. Tetrahedron. Lett. 1997, 38, 2045-2048.

(17) Of note, Procter and his group reported very recently the first catalytic use of $\mathrm{SmI}_{2}$, avoiding the need of stoichiometric co-reductant and additives, in a cyclization cascade by radical relay. See : Huang, H.-M.; Mc Dovall, J. J. W.; Procter, D. J. Nat. Catal. 2019, 2, 211-218.

(18) (a) Frisch, A. C.; Beller, M. Catalysts for Cross-Coupling Reactions with Non-activated Alkyl Halides. Angew. Chem. Int. Ed. 2005, 44, 674-688. (b) Rudolph, A.; Lautens, M. Secondary Alkyl Halides in Transition-Metal-Catalyzed Cross-Coupling Reactions. Angew. Chem. Int. Ed. 2009, 48, 2656-2670. (c) Jana, R.; Pathak, T. P.; Sigman, M. S. Advances in Transition Metal (Pd,Ni,Fe)-Catalyzed Cross-Coupling Reactions Using Alkyl-organometallics as Reaction Partners. Chem. Rev. 2011, 111, 1417-1492. 